\title{
Penerapan Aplikasi Smart Green Spatial Database untuk Meningkatkan Transaksi Penjualan dalam Bisnis Baru Pembibitan Jamur sebagai Upaya Pemberdayaan Masyarakat Terdampak Covid-19
}

\author{
Rindra Yusianto, Wisnu Adi Prasetyanto ${ }^{2}$, Herwin Suprijono ${ }^{3}$, Kusni Ingsih ${ }^{4}$ \\ 1 Program Studi Teknik Industri, Universitas Dian Nuswantoro, Semarang \\ 2,3Program Studi Teknik Elektro, Universitas Dian Nuswantoro, Semarang \\ 4Program Studi Manajemen, Universitas Dian Nuswantoro, Semarang \\ e-mail: 1rindra@staff.dinus.ac.id, 2winsuadip@dsn.dinus.ac.id, \\ 3herwin.suprijono@dsn.dinus.ac.id, 4kusni.ingsih@dsn.dinus.ac.id
}

\begin{abstract}
Abstrak
Jamur tiram (Pleurotus ostreatus) merupakan salah satu komoditas yang banyak dijumpai di sejumlah kelurahan di Kota Semarang. Terdapat 18 kelompok tani (poktan) yang fokus budidaya jamur tiram. Pemerintah Kota Semarang telah mengalokasikan sejumlah dana untuk pengembangan komoditas ini. Namun adanya pandemi COVID-19, muncul sejumlah kendala yaitu pengadaan bibit, pemasaran hasil panen, dan diversifikasi bisnis baru yaitu pembibitan yang sebenarnya memiliki prospek yang baik di masa pandemi ini. Sampel kegiatan ini adalah 30 orang penangkar bibit dan pembudidaya jamur tiram anggota Poktan Bhumi Rejo Makmur, Omah Jamur dan Jamur Sodong menggunakan teknik simple random sampling. Berdasarkan pengumpulan data dengan cara diskusi dan wawancara mendalam, didapat hasil bahwa pandemi COVID-19 berpengaruh terhadap usaha. Selain pemasaran, bibit berkualitas juga sulit didapatkan. Saat ini poktan tidak menggunakan sistem informasi dalam upaya untuk meningkatkan penjualan dan kapasitas produksi masih sangat rendah yaitu sekali proses hanya 100 baglog. Kami menyusun dan mendiseminasikan arsitektur produk teknologi smart green spatial database untuk bisnis baru pembibitan jamur dengan pendekatan basis data spasial. Sebaran pembudidaya jamur, penangkar bibit berkualitas, segmen pasar potensial dan jangkauan pasar digambarkan dalam Geographic Information System (GIS). Sistem pendukung keputusan dan teknologi yang kami transfer ke mitra dalam bentuk smart green spatial database. Dengan smart green spatial database dapat meningkatkan transaksi penjualan dalam bisnis baru pembibitan jamur yaitu dari 18 poktan, ada 17 poktan yang sudah memulai usaha pembibitan, adanya peningkatan jumlah pemasok bibit menjadi 6 penangkar bibit, adanya peningkatan kapasitas produksi menjadi 400 baglog dan jangkauan pemasaran mulai terdistribusi ke luar Jawa Tengah.
\end{abstract}

Kata Kunci: jamur tiram, database, pembibitan jamur, COVID-19 


\begin{abstract}
Oyster mushroom (Pleurotus ostreatus) is an agricultural commodity in Semarang, Central Java, Indonesia. There are 18 farmer groups (poktan) that focus on oyster mushroom cultivation. Semarang City Government has allocated a number of funds for the development of this commodity. However, with the COVID-19 pandemic, a number of obstacles emerged, namely the procurement of seeds, marketing of crops, and diversification of new businesses, namely nurseries that actually have good prospects during this pandemic. The sample of this activity was 30 seed breeders and oyster mushroom cultivators, members of Poktan Bhumi Rejo Makmur, Omah Jamur and Jamur Sodong using simple random sampling technique. Based on data collection with in-depth discussions and interviews, the COVID-19 pandemic is affecting businesses. Apart from marketing, quality seeds are also difficult to find. Currently, poktan do not use information systems in an effort to increase sales and production capacity is still very low, which is only 100 baglogs at one time. We compile and disseminate a smart green spatial database technology product architecture for a new mushroom nursery business with a spatial database approach. The distribution of mushroom cultivators, quality seed breeders, potential market segments and market reach is described in the Geographic Information System (GIS). Decision support systems and technology that we transfer to partners in the form of a smart green spatial database. With a smart green spatial database, it can increase sales transactions in the new mushroom nursery business, namely from 18 farmer groups, 17 farmer groups that have started a nursery business, an increase in the number of seed suppliers to 6 seed breeders, an increase in production capacity to 400 baglogs and a distributed marketing reach to outside Central Java.
\end{abstract}

Keywords: oyster mushroom, database, mushroom nursery, COVID-19

\title{
Pendahuluan
}

Jamur tiram (Pleurotus ostreatus) adalah sejenis jamur kayu yang biasanya tumbuh di daerah dengan kelembaban tinggi (Suryawati et al., 2019; Kurniati et al., 2019). Kegunaan utamanya sebagai bahan makanan non kolesterol dengan nilai gizi tinggi (Umniyatie et al., 2013; Anita et al., 2015). Diversifikasi pasca panen cukup banyak, dapat dijual dalam bentuk segar, kering, kaleng serta diolah menjadi keripik, krispi, pepes, tumis dan nugget (Tjokrokusumo et al. 2016). Jamur ini merupakan salah satu komoditas yang banyak dijumpai di sejumlah kelurahan di Kota Semarang. Di Kota Semarang terdapat 18 kelompok tani (poktan) yang fokus budidaya jamur tiram dan tersebar di 16 kecamatan. 6 kecamatan yang paling baik dalam budidaya jamur tiram di Kota Semarang adalah Gajahmungkur, Ngaliyan, Gunungpati, Semarang Selatan, Pedurungan dan Mijen. Ke-18 poktan tersebut tergabung dalam Gabungan Kelompok Tani (Gapoktan) Jamur Tiram Kota Semarang.

\section{Profil Mitra}

Ketua kelompok Gapoktan Jamur Tiram Kota Semarang yaitu Bapak Heru Djoenaedi pengelola poktan Bhumi Rejo Makmur beralamat di dusun Karangbendo No. 13 RT 14 RW 01 Kecamatan Gajahmungkur Semarang yang menjadi mitra dalam program ini. Produksi sebelum COVID-19 adalah 100 baglog dengan kapasitas panen $25 \mathrm{~kg} /$ hari. Wilayah pemasaran yaitu Semarang, Salatiga, Demak dan Boyolali. 
Namun dengan adanya pandemi COVID-19 ini muncul sejumlah kendala yaitu pengadaan bibit berkualitas dan pemasaran hasil panen. Sebagian besar anggota poktan belum mempunyai pengetahuan memproduksi jamur tiram menjadi produk unggulan yang mempunyai nilai jual tinggi, produksi yang berkelanjutan serta penanganan pasca panen yang baik. Termasuk diversifikasi bisnis baru yaitu pembibitan yang sebenarnya memiliki prospek yang baik di masa pandemi COVID19 ini. Oleh sebab itu dalam kegiatan program pemberdayaan masyarakat ini diimplementasikan sejumlah kegiatan pengembangan usaha poktan melalui pembibitan jamur sehingga diharapkan jamur ini akan menjadi produk unggulan Kota Semarang berbasis database. Dengan smart green spatial database diharapkan dapat meningkatkan transaksi penjualan dalam bisnis baru pembibitan jamur sebagai upaya pemberdayaan masyarakat terdampak COVID-19.
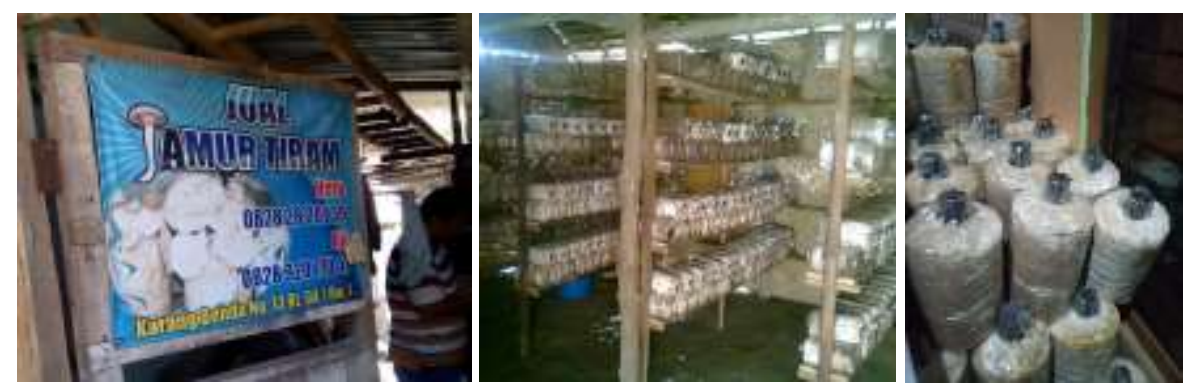

Gambar 1. Baglog Produksi Poktan Bhumi Rejo Makmur

\section{Persoalan yang dihadapi Mitra}

Sampel penelitian adalah 30 orang penangkar bibit dan pembudidaya jamur tiram anggota Poktan Bhumi Rejo Makmur, Omah Jamur Ungaran dan Jamur Sodong Ambarawa menggunakan teknik simple random sampling. Berdasarkan pengumpulan data dengan cara diskusi dan wawancara mendalam, didapatkan informasi bahwa pandemi COVID-19 berpengaruh terhadap usaha. Selain pemasaran, bibit berkualitas juga sulit didapatkan. Saat ini poktan tidak menggunakan sistem informasi pendukung keputusan cerdas dalam upaya untuk meningkatkan penjualan dan kapasitas produksi masih sangat rendah yaitu sekali proses hanya 100 baglog. Pemerintah Kota Semarang telah mengalokasikan sejumlah dana untuk pengembangan komoditas ini, salah satunya melalui kegiatan penyuluhan. Namun kegiatan ini belum sampai kepada upaya optimalisasi peran poktan dalam rangka mendiseminasikan program produktivitas komoditas jamur tiram menjadi komoditas unggulan meliputi penyuluhan tata cara diseminasi program dan pendampingan poktan, sehingga diperlukan kegiatan peningkatan kapasitas proses produksi dengan bebasis database, yang meliputi database penangkar bibit berkualitas, database segmen pasar, dan database zona wilayah spasial potensi pemasaran.

\section{Metode}

Metode pelaksanaan kegiatan yang telah dilakukan dalam program pemberdayaan masyarakat ini adalah sebagai berikut: 


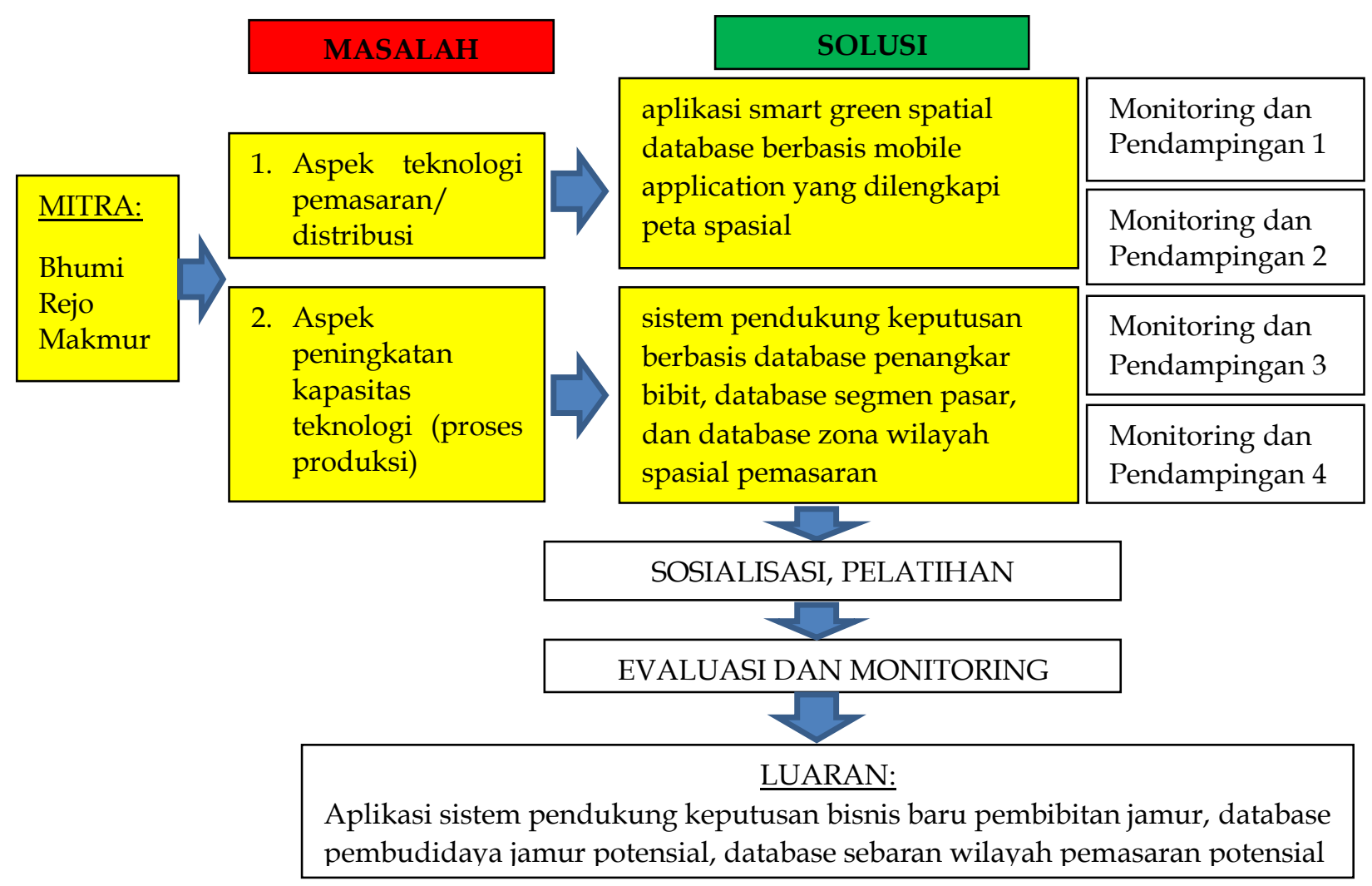

Gambar 2. Metode dan Tahapan Pelaksanaan Kegiatan

Kami menyusun arsitektur produk teknologi smart green spatial database untuk bisnis baru pembibitan jamur dengan pendekatan basis data spasial. Sebaran pembudidaya jamur, penangkar bibit berkualitas, segmen pasar potensial dan jangkauan pasar digambarkan dalam Geographic Information System (GIS). Kami melakukan segregasi dengan Geo Segregation Analyzer untuk mendapatkan informasi statistik berdasarkan basis data spasial (Yusianto et al. 2020b). Produk akhir adalah sistem pendukung keputusan dalam bentuk smart green spatial database yang dapat membantu anggota poktan untuk memulai usaha baru pembibitan jamur bersumber data valid berbasis database. Saat ini kami sudah mengumpulkan database spasial sebaran pembudidaya jamur dan penangkar bibit berkualitas, merancang database spasial dan mulai membuat aplikasi berbasis Android.

\section{Hasil dan Pembahasan}

Kegiatan ini dilaksanakan pada tanggal 7 September 2020 sampai dengan 29 November 2020. Hasil kegiatan menunjukkan bahwa pembibitan merupakan rangkaian kegiatan paling menentukan dalam usaha budidaya jamur tiram. Tidak semua pengusaha jamur memiliki kemampuan untuk menghasilkan bibit unggul.

\section{Proses Penangkaran Bibit Jamur}

Dalam kegiatan ini, analisis dan proses pembibitan jamur dilakukan dengan mengamati dan studi lapangan dengan tetap menjaga protokol Kesehatan di beberapa penangkar bibit, diantaranya Omah Jamur Ungaran. Sebagai penangkar 
bibit mulai dari F0, F1, F2 dan F3, Omah Jamur Ungaran juga memasok bibit ke Poktan Bhumi Rejo Makmur. Ke Poktan ini, bibit yang dipasok adalah kualitas F2 dn F3. Adapun proses pembibitan di penangkar bibit dengan tetap menjaga protokol kesehatan adalah sebagai berikut:

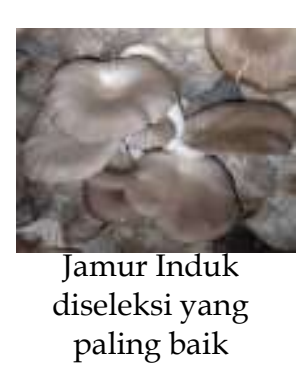

paling baik
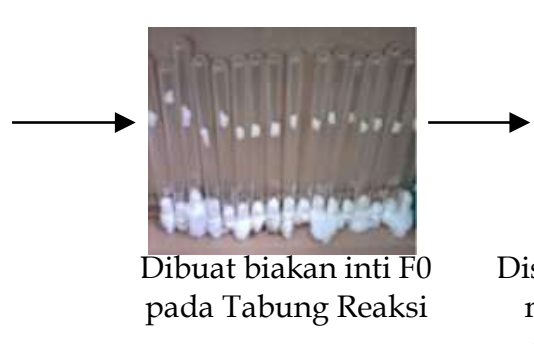
menjadi indukan F1

(1 tabung reaksi F0 menjadi 4-6 botol $600 \mathrm{ml}$ indukan F1)

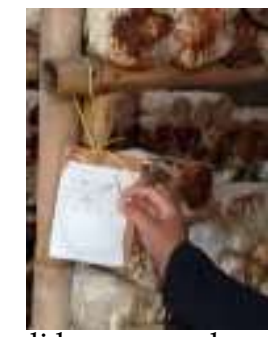

Ditata di kumpung dan memunggu miselium memenuhi baglog dan proses tumbuh. Untuk memudahkan identifikasi, setiap baris baglog diberikan label tanggal penyemaian indukan F3 pertama kalinya

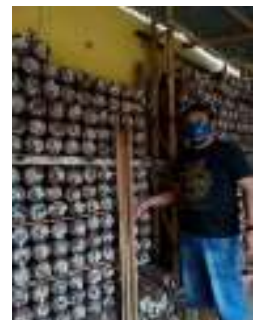

$$
4
$$

Gambar 3. Proses Penangkaran Bibit Jamur

\section{Sebaran Database Spasial Penangkar Bibit}

Aplikasi yang kami buat berbasis android dengan visualiasi peta lokasi, termasuk koordinat penangkar bibit. Aplikasi ini memudahkan pengguna untuk mengambil keputusan yang lebih baik (Yusianto et al., 2020). Kami sudah membuat database spasial berbasis koordinat longitude dan latitude. Database ini terdiri dari tabel-tabel database yang mengakomodasi database penangkar bibit, database segmen pasar, dan database zona wilayah spasial pemasaran Sebaran spasial penangkar bibit jamur seperti pada Tabel 1 dan Gambar 4 berikut ini.

Tabel 1. Sebaran Database Spasial Penangkar Bibit Periode September - November 2020

\begin{tabular}{|c|l|l|l|}
\hline No & Nama Penangkar Bibit & Kabupaten & Koordinat Spasial \\
\hline 1 & Omah Jamur Ungaran & Kab. Semarang & $-7.142708543805956,110.42086894228474$ \\
\hline 2 & Rumah Bibit Jamur Sodong & Kab. Semarang & $-7.26095835280036,110.3252461542115$ \\
\hline 3 & Lentera Fajar & Kab. Boyolali & $-7.513099273343897,110.60821027338804$ \\
\hline 4 & Barokah Mushroom & Kab. Boyolali & $-7.372234593238017,110.63644399654075$ \\
\hline 5 & Jamur Tiram Jogonalan & Kab. Klaten & $-7.7479918159592005,110.54703762090473$ \\
\hline 6 & Jati Nikmat Fungus Farm & $\begin{array}{l}\text { Kota } \\
\text { Semarang }\end{array}$ & $-7.063427302127881,110.41403221069487$ \\
\hline
\end{tabular}


Adapun peta visual penangkar bibit adalah sebagai berikut:

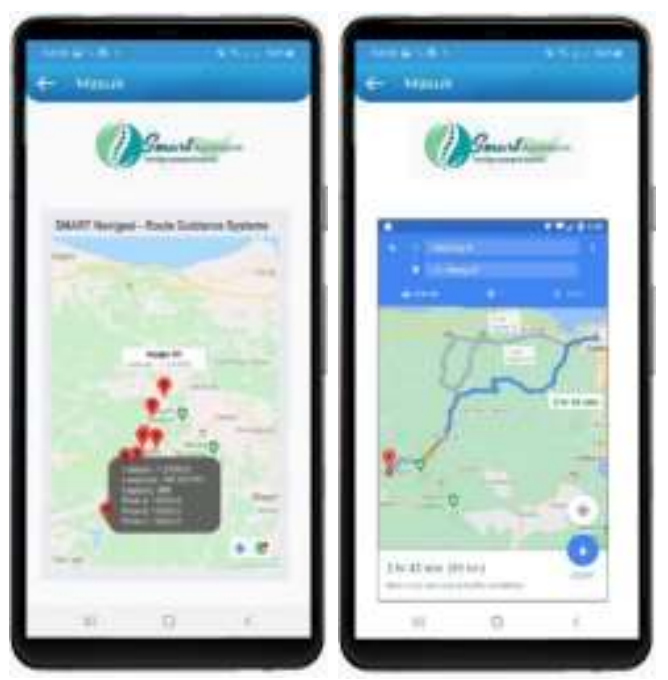

Gambar 4. Titik Lokasi Koordinat Spasial Penangkar Bibit

\section{Aplikasi Smart Green Spatial Database Berbasis Mobile Application}

Aplikasi smart green spatial database sebagai produk akhir dari kegiatan ini sudah diaplikasikan. Layout aplikasi dapat digunakan untuk masing-masing user yaitu: petani penagkar bibit, collection center (agen), retail dan konsumen. Adapun sampel mockup aplikasi berbasis Android adalah sebagai berikut:

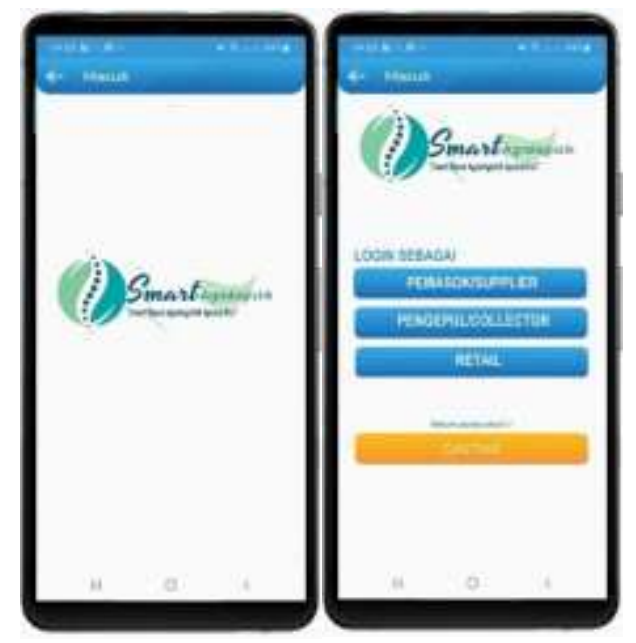

Gambar 5. Halaman Awal Aplikasi 


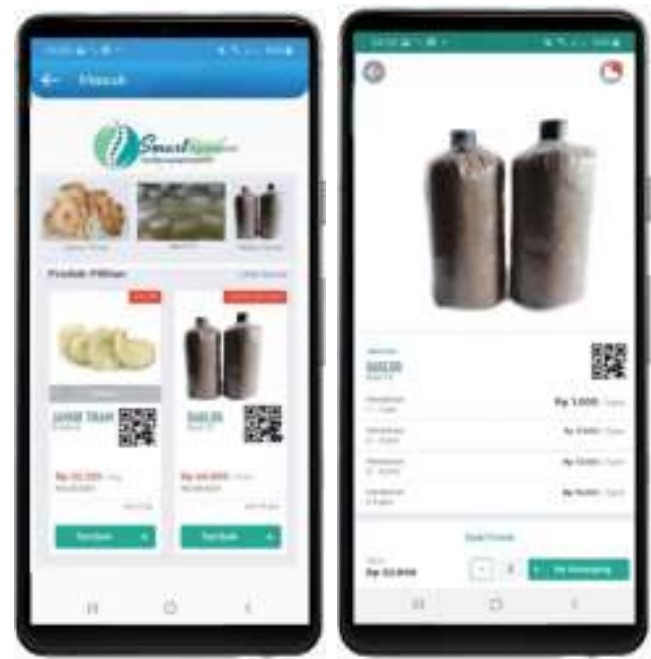

Gambar 6. Halaman Transaksi Penjualan dan Detail Produk

\section{Dampak Ekonomi dan Sosial}

Melalui tahap awal pelaksanaan program, minat anggota poktan untuk memulai bisnis baru pembibitan jamur semakin meningkat. Berdasarkan wawancara awal, dari 18 poktan, ada 17 poktan yang siap untuk memulai usaha baru. Sedangkan 1 poktan saat ini fokus untuk memperbaiki pemasaran. Berikut grafik kesiapan poktan sebelum dan sesudah program dilaksanakan.

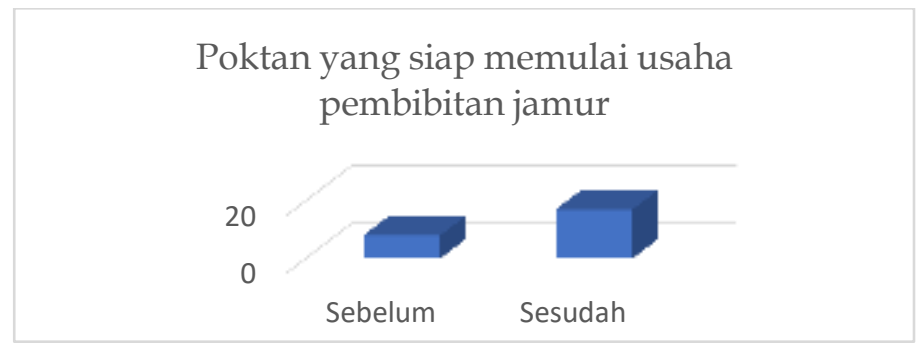

Grafik 1. Kesiapan Poktan Sebelum dan Sesudah Program Dilaksanakan

Jangkauan pemasaran mulai terdistribusi ke luar Jawa Tengah. Berikut dokumentasi pengiriman ke beberapa kota di luar Jawa Tengah, diantaranya ke Cianjur Jawa Barat dan DIY.
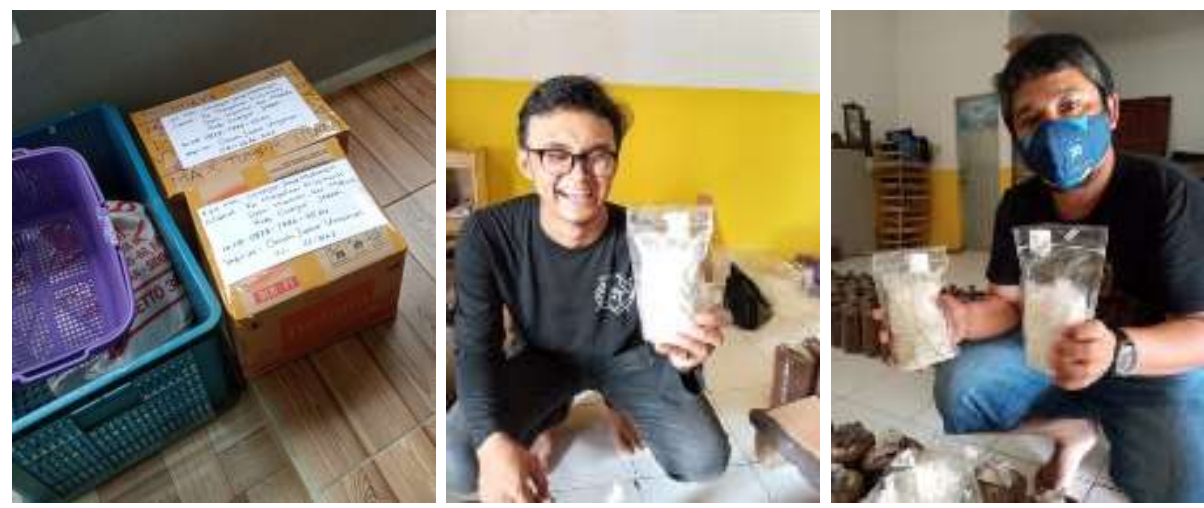

Gambar 7. Dokumentasi Proses Pengiriman 
Dengan adanya sosialisasi dan penjelasan mendalam terkait bibit yang berkualitas, maka hubungan antara anggota poktan dengan penangkar bibit semakin baik. Terbukti awalnya hanya 3 penangkar bibit yag memasok bibit, saat ini ada 6 pemasok.

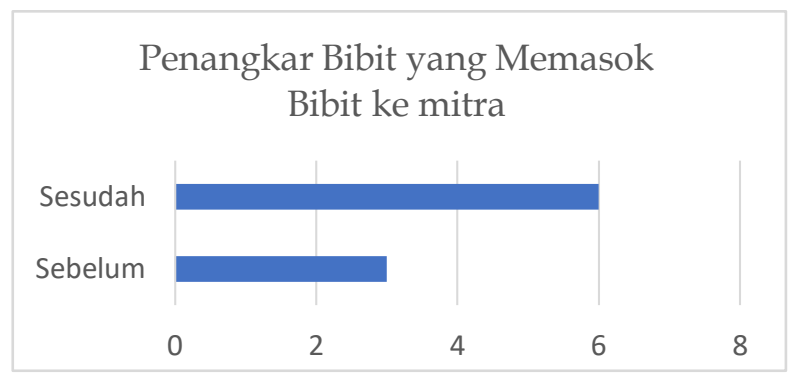

Grafik 2. Grafik Perkembangan Penangkar Bibit yang memasok biit ke mitra

Selain itu, dengan adanya kegiatan ini maka transaksi penjualan semakin meningkat, ditunjukkan dengan meningkatnya kapasitas produksi yaitu sekali produksi menghasilkan 400 baglog.

\section{Kontribusi Mitra terhadap Pelaksanaan Program}

Kontribusi mitra dalam pelaksanaan program pemberdayaan masyarakat ini adalah sebagai berikut:

a. Mitra poktan Bhumi Rejo Makmur terlibat langsung dalam program. Keterlibatan mitra dalam pelaksanaan program ini yaitu mulai dari tahap awal diskusi penyusunan database dan sosialisasi.

b. Mitra mengijinkan beberapa alat untuk digunakan sebagai pendukung pelaksanaan program ini.

\section{Simpulan dan Rekomendasi}

Saat ini poktan tidak menggunakan sistem informasi dalam upaya untuk meningkatkan penjualan dan kapasitas produksi masih sangat rendah. Kami menyusun dan mendiseminasikan arsitektur produk teknologi smart green spatial database untuk bisnis baru pembibitan jamur dengan pendekatan basis data spasial. Sebaran pembudidaya jamur, penangkar bibit berkualitas, segmen pasar potensial dan jangkauan pasar digambarkan dalam GIS. Sistem pendukung keputusan yang kami transfer teknologi ke mitra dalam bentuk smart green spatial database yang dapat membantu anggota poktan untuk memulai usaha baru pembibitan jamur dengan bersumber database yang valid. Dengan smart green spatial database dapat meningkatkan transaksi penjualan dalam bisnis baru pembibitan jamur sebagai upaya pemberdayaan masyarakat terdampak COVID-19, dari 18 poktan, ada 17 poktan yang siap memulai usaha baru, adanya peningkatan jumlah pemasok bibit menjadi 6 penangkar bibit, adanya peningkatan kapasitas produksi menjadi 400 baglog sekali produksi dan jangkauan pemasaran mulai terdistribusi ke luar Jawa Tengah. 


\section{Penghargaan}

Terima kasih kepada Kementerian Ristek dan Teknologi/Brin yang telah mendanai kegiatan ini melalui Program Pemberdayaan Masyarakat Skema UKM Indonesia Bangkit Tahun Anggaran 2020.

\section{Daftar Pustaka}

Anita L, Sagala B, Risanti M, Kurniati M. 2015. Pembuatan Bibit Jamur Tiram Putih dengan Melibatkan Remaja di Desa Situ Ilir (Manufacture of Oyster Mushroom Seeds Involving Teenagers at Situ Ilir Village). Agrokreatif. 1(11):81-87.

Kurniati F, Sunarya Y, Nurajijah R. 2019. Pertumbuhan dan Hasil Jamur Tiram Putih (Pleurotus ostreatus (Jacq) P. Kumm) pada berbagai Komposisi Media Tanam. Media Pertan. 4(2):59-68.

Suryawati E, Putra RA, Taufik H. 2019. Budidaya Jamur Tiram dan Olahannya untuk Kemandirian Masyarakat Desa Desa Seko Lubuk Tigo secara administratif berada di Kecamatan Lirik, Kabupaten Metode yang digunakan dalam kegiatan ini sesuai dengan diskusi tim abdi. J Pengabdi Kpd Masy. 5(3):358-370.

Tjokrokusumo D, Widyastuti N, Giarni R. 2016. Diversifikasi produk olahan jamur tiram (Pleurotus ostreatus) sebagai makanan sehat. Di dalam: Seminar Nasional Masyarakat Biodiversivikasi Indonesia. hlm 2015-2020.

Umniyatie S, Astuti, Pramiadi D, Henuhili V. 2013. Budidaya Jamur Tiram (Pleuretus.sp) sebagai Alternatif Usaha bagi Masyarakat Korban Erupsi Merapi di Dusun Pandan, Wukirsari, Cangkringan, Sleman DIY. Inotek. 17(2):162-175.

Yusianto R, Marimin, Suprihatin, Hardjomidjojo H. 2020a. The Route Guidance System using Android-Based Navigation to Determine the Shortest Potatoes Distribution Route. Int Semin Appl Technol Inf Commun. 1(1):320-326.

Yusianto R, Marimin, Suprihatin, Hardjomodjojo H. 2020b. Spatial Analysis for Crop Land Suitability Evaluation: A Case Study of Potatoes Cultivation in Wonosobo, Indonesia. Int Sem Ina Appl Technol Inf Commun. 1(1):313-319. 